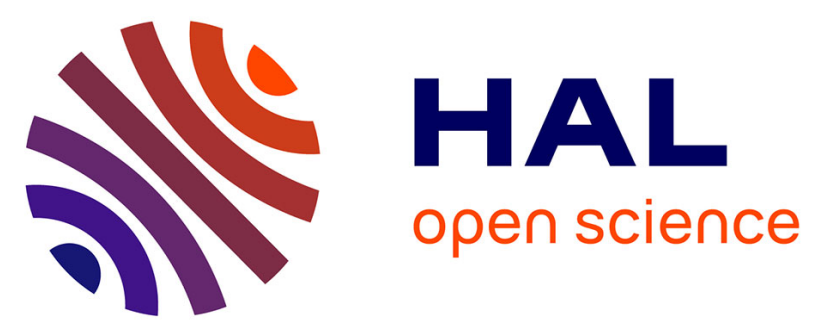

\title{
Comparative pharmacology and computational modelling yield insights into allosteric modulation of human $\alpha 7$ nicotinic acetylcholine receptors
}

\author{
David B. Sattelle, Steven D. Buckingham, Miki Akamatsu, Kazuhiko
}

Matsuda, Ilse Pienaar, Andrew K. Jones, Benedict M. Sattelle, Andrew

Almond, Charles D. Blundell

\section{To cite this version:}

David B. Sattelle, Steven D. Buckingham, Miki Akamatsu, Kazuhiko Matsuda, Ilse Pienaar, et al.. Comparative pharmacology and computational modelling yield insights into allosteric modulation of human $\alpha 7$ nicotinic acetylcholine receptors. Biochemical Pharmacology, 2009, 78 (7), pp.836. 10.1016/j.bcp.2009.06.020 . hal-00509508

\section{HAL Id: hal-00509508 https://hal.science/hal-00509508}

Submitted on 13 Aug 2010

HAL is a multi-disciplinary open access archive for the deposit and dissemination of scientific research documents, whether they are published or not. The documents may come from teaching and research institutions in France or abroad, or from public or private research centers.
L'archive ouverte pluridisciplinaire HAL, est destinée au dépôt et à la diffusion de documents scientifiques de niveau recherche, publiés ou non, émanant des établissements d'enseignement et de recherche français ou étrangers, des laboratoires publics ou privés. 


\section{Accepted Manuscript}

Title: Comparative pharmacology and computational modelling yield insights into allosteric modulation of human $\alpha 7$ nicotinic acetylcholine receptors

Authors: David B. Sattelle, Steven D. Buckingham, Miki Akamatsu, Kazuhiko Matsuda, Ilse Pienaar, Andrew K. Jones,

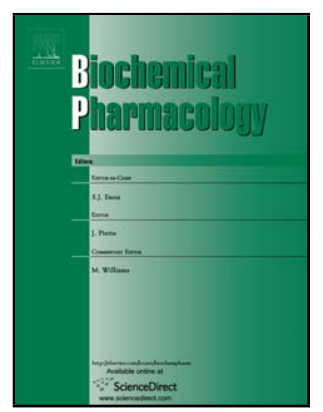
Benedict M. Sattelle, Andrew Almond, Charles D. Blundell

PII: S0006-2952(09)00489-4

DOI: doi:10.1016/j.bcp.2009.06.020

Reference: BCP 10229

To appear in: $\quad B C P$

Received date: $\quad$ 27-4-2009

Revised date: $\quad$ 15-6-2009

Accepted date: $\quad$ 15-6-2009

Please cite this article as: Sattelle DB, Buckingham SD, Akamatsu M, Matsuda K, Pienaar I, Jones AK, Sattelle BM, Almond A, Blundell CD, Comparative pharmacology and computational modelling yield insights into allosteric modulation of human $\alpha 7$ nicotinic acetylcholine receptors, Biochemical Pharmacology (2008), doi:10.1016/j.bcp.2009.06.020

This is a PDF file of an unedited manuscript that has been accepted for publication. As a service to our customers we are providing this early version of the manuscript. The manuscript will undergo copyediting, typesetting, and review of the resulting proof before it is published in its final form. Please note that during the production process errors may be discovered which could affect the content, and all legal disclaimers that apply to the journal pertain. 


\section{Comparative pharmacology and computational modelling yield insights into allosteric modulation of human $\alpha 7$ nicotinic acetylcholine receptors}

David B. Sattelle ${ }^{\mathrm{a} *}$, Steven D. Buckingham ${ }^{\mathrm{a}}$, Miki Akamatsu ${ }^{\mathrm{b}}$, Kazuhiko Matsuda $^{\mathrm{c}}$, Ilse Pienaar ${ }^{\mathrm{a}}$, Andrew K. Jones ${ }^{\mathrm{a}}$, Benedict M. Sattelle ${ }^{\mathrm{d}}$, Andrew Almond ${ }^{\mathrm{d}}$ and Charles D. Blundell ${ }^{\mathrm{e}}$

${ }^{\mathrm{a}}$ MRC Functional Genomics Unit, Department of Physiology, Anatomy and Genetics, University of Oxford, South Parks Road, Oxford, Oxford OX1 3QX, UK. david.sattelle@,dpag.ox.ac.uk, steven.buckingham@dpag.ox.ac.uk, ilse.pienaar@dpag.ox.ac.uk, andrew.jones@dpag.ox.ac.uk

${ }^{\mathrm{b}}$ Graduate School of Agriculture, Kyoto University, Kita-Shirakawa, Sakyo-ku, Kyoto, 6068502, Japan. akamatsu@kais.kyoto-u.ac.jp

${ }^{\mathrm{c}}$ Department of Applied Biological Chemistry, Faculty of Agriculture, Kinki University, 3327204 Nakamachi, Nara 631-8505, Japa kmatsuda@nara.kindai.ac.jp

${ }^{\mathrm{d}}$ Manchester Interdisciplinary Biocentre, 131 Princess Street, Manchester M1 7DN, UK. ben.sattelle@,manchester.ac.uk, andrew.almond@manchester.ac.uk

${ }^{\mathrm{e}}$ Conformetrix Ltd., Core Technology Facility, 46 Grafton Street, Manchester, M13 9NT, UK. charles.blundell@,conformetrix.com

For submission to Biochemical Pharmacology Special Issue 'Nicotinic Acetylcholine Receptors as Therapeutic Targets: Frontiers in Basic Research and Clinical Science’ Oct 14-16 Chicago USA (Satellite meeting prior to Society for Neuroscience 2009 Meeting, Chicago)

*Corresponding author and presenting author Tel: 44 (0)-1865-272145; Fax: 44(0)-1865285862; Email: david.sattelle@dpag.ox.ac.uk 


\begin{abstract}
The human $\alpha 7$ nicotinic acetylcholine receptor (nAChR) subunit and its Caenorhabditis elegans homolog, ACR-16, can generate functional recombinant homomeric receptors when expressed in Xenopus laevis oocytes. Both nAChRs express robustly in the presence of the co-injected chaperone RIC-3 and show striking differences in the actions of a type I positive allosteric modulator (PAM), ivermectin (IVM). Type I PAMs are characterised by an increase in amplitude only of the response to acetylcholine (ACh), whereas type II PAMs exhibit, in addition, changes in time-course / desensitization of the ACh response. The type I PAMs, ivermectin, 5-hydroxyindole (5-HI), NS-1738 and genistein and the type II PAM, PNU-120596, are all active on human $\alpha 7$ but are without PAM activity on ACR-16, where they attenuate the amplitude of the ACh response. We used the published structure of avermectin Bla to generate a model of IVM, which was then docked into the candidate transmembrane allosteric binding site on $\alpha 7$ and ACR-16 in attempt to gain insights into the observed differences in IVM actions. The new pharmacological findings and computational approaches being developed may inform the design of novel PAM drugs targeting major neurological disorders.
\end{abstract}

Keywords: computational modeling, electrophysiology, ivermectin, nicotinic acetylcholine receptor, positive allosteric modulators, ion channels 


\section{Introduction}

Nicotinic acetylcholine receptors (nAChRs) containing the $\alpha 7$ subunit are widely expressed in human brain regions associated with cognitive functions [1-3]. This subtype of $\mathrm{nAChR}$ has major pre-synaptic roles in the brain [4], which include regulating the release of dopamine from nerve terminals in the dopaminergic reward pathway $[5,6]$. The activation of $\alpha 7 \mathrm{nAChRs}$ is neuroprotective against toxicity resulting from exposure to the neurotoxic $\beta$-amyloid peptide, A $\beta 1-42$, important in Alzheimer's disease and other toxins [7]. The $\alpha 7 \mathrm{nAChRs}$ participate in auditory sensory gating, defects in which contribute to the attention and cognitive problems associated with schizophrenia $[8,9]$. They are also involved in the mechanism of nicotine addiction [10]. The $\alpha 7 \mathrm{nAChR}$ subunit, which forms robust functional homomeric receptors, has been proposed as a candidate target for new drugs designed to ameliorate symptoms of Alzheimer's disease and schizophrenia as well as to control pain [11].

A number of $\alpha 7$-specific agonists have been designed with therapeutic goals in mind but this strategy raises concerns relating to long-term drug activation and / or rapid desensitization of nAChRs, which may compromise the utility of such ligands. In attempts to circumvent such problems, positive allosteric modulators of the $\alpha 7 \mathrm{nAChR}$ have been generated, which act by enhancing the actions of the neurotransmitter acetylcholine (ACh) [11]. Such drugs offer a therapeutic approach to cognitive and attention deficits, which, importantly, preserve the integrity of cholinergic neurotransmission [12]. Two classes of positive allosteric modulators (PAMs) can be recognised in terms of their actions on $\alpha 7$ nAChRs $[11,13]$. Type I PAMs enhance the amplitude of the response to ACh with little or no effect on the time-course of the response, including desensitization. Examples include ivermectin (IVM), genistein, 5hydroxyindole (5-HI), compound-6 and NS-1738. Type II PAMs, such as PNU-120596, and the 
tetrahydroquinoline, 4-naphthalene-1-yl-3a,4,5,9b-tetrahydro-3-H-cyclopenta[c]quinoline-8sulfonic acid amide (TQS). In addition to enhancing the amplitude of ACh responses, Type II PAMs also greatly prolong the time-course of $\alpha 7$-mediated ACh responses [13].

The discovery that NS-1738 and PNU-120596 are selective for $\alpha 7$, yet show quite different PAM actions suggests that different sites of action on the receptor may exist [14]. Regions important in the actions of these drugs have been explored using chimeras of the $\alpha 7$ and the 5-HT3A cys-loop receptor subunits, both of which exhibit homomer-forming capacity. Based on studies of PNU120596 and NS-1738, Bertrand and colleagues conclude that there may be different binding sites for different allosteric modulators, each with a distinct profile of drug sensitivities [14]. They also highlight an important role in the actions of these allosteric modulators [14] of a short sequence (AEIMPATSDS) in human $\alpha 7$ at the M2 / M2-M3 loop interface, equivalent to the region (SDTLPATAIG) of the 5-HT3A receptor. In a separate study, Millar and colleagues have suggested that there may be a common site of action for two PAMs PNU-120596 and LY2087101 [15]. These authors also used $\alpha 7$ / 5-HT3 chimeras, identifying the transmembrane (TM) regions as critical in drug enhancement of agonist evoked responses. In particular, 5 residues ( 2 in TM1, 1 in TM2 and 2 in TM4) strongly influence the actions of PAMs. Although mutating all these residues in the $\alpha 7 \mathrm{TM}$ sequence to their 5HT3A equivalents strongly reduced the allosteric actions of these drugs, such activity could not be restored by incorporating the $\alpha 7$ resides into the equivalent site of the 5-HT3A receptor subunit.

Experiments on chimeras have been extremely fruitful but are not without their problems. For example, some are poorly expressed, suggesting that they may not be correctly folded, thereby 
complicating interpretation of the results. In addition, the functional organization of receptor domains may not be perfectly modular, so that the effects of substituting a domain may include indirect effects on other, unchanged domains. This may be a particular concern when interspecies chimaeras are used. A complementary approach is to explore the comparative pharmacology of evolutionarily remote members of the same superfamily of cys-loop ligandgated ion channels. This strategy has already proved instructive in accelerating the identification of drug targets. For example, the hitherto elusive steroid site on the GABA receptor was identified in a comprehensive comparison between Drosophila melanogaster GABA-gated chloride channels and human $\mathrm{GABA}_{\mathrm{A}}$ type receptors [16]. We have previously shown that the anthelmintic compound, IVM, enhanced ACh-induced $\alpha 7$ amplitude responses, confirming the earlier finding of Bertrand and colleagues [17], while slightly attenuating responses of ACR-16 [18], a Caenorhabditis elegans $\alpha 7$ homologue $[19,20]$. ACR-16 and $\alpha 7 \mathrm{nAChR}$ subunits share considerable amino acid sequence identity of $47 \%$ but show important differences in residues considered important in allosteric drug actions (Fig. 1). For example, of the 5 transmembrane residues identified by Millar and colleagues in rat $\alpha 7$ (S222, A225, M253, F455 and C459 using mature peptide numbering) only F455 is conserved in C. elegans ACR-16 (F458 in ACR-16, Fig.1) [15]. Here, we report comparison of the actions of several other PAMs on the human $\alpha 7$ nAChR and ACR-16. Having established that these two receptors differ greatly in their sensitivity to PAMs, we then modeled the docking of IVM to the transmembrane regions of both receptors in an initial attempt to develop a molecular interpretation of the observed differences in pharmacology.

\section{Materials and Methods}




\subsection{Electrophysiological studies}

The vectors pcDNA3.1/Zeo+ (Invitrogen) encoding human $\alpha 7$ or C. elegans ric-3 as well as pGEM-T Easy (Promega) encoding acr-16 were used. The vectors were linearised to be used as template for cRNA synthesis with the T7 (pCDNA3.1) or SP6 (pGEM-T Easy) mMESSAGE mMACHINE kits (Ambion). Mature stage IV or V Xenopus laevis oocytes were manually defolliculated after incubation for $1 \mathrm{~h}$ in $2 \mathrm{mg} / \mathrm{ml}$ collagenase (Sigma type IV) in calcium-free oocyte saline (OS) (containing (in $\mathrm{mM}$ ) NaCl, 100; KCl, 2; $\mathrm{CaCl}_{2}, 1.8 ; \mathrm{MgCl}_{2}, 1 ; \mathrm{HEPES}, 5$ adjusted to $\mathrm{pH} 7.6$ with $5 \mathrm{M} \mathrm{NaOH}$ ). Following defolliculation, the cytoplasm of each oocyte was injected with 50nl 1ng/nl containing a 5:1 ratio of receptor cRNA: RIC-3 cRNA in RNAasefree $\mathrm{dH}_{2} \mathrm{O}$. Oocytes were incubated for 2-7 days in filter-sterilized culture medium consisting of OS supplemented with 100 units $/ \mathrm{ml}$ of penicillin, $100 \mu \mathrm{g} / \mathrm{ml}$ of streptomycin and $50 \mu \mathrm{g} / \mathrm{ml}$ gentamycin sulphate and $2.5 \mathrm{mM}$ sodium pyruvate, the medium being changed daily. After 2-7 days incubation, injected oocytes were transferred to a recording chamber (Warner type RC-3Z) for electrophysiological analysis. Oocytes were impaled with two glass microelectrodes (3M $\mathrm{KCl}$, resistance $0.5-1 \mathrm{M} \Omega$ in $\mathrm{OS}$ ) and held under voltage clamp at -100 $\mathrm{mV}$. Standard twoelectrode voltage clamp was achieved using an Axon Axoclamp 900A amplifier under the control of a laboratory PC. Signals were acquired at $1 \mathrm{kHz}$.

Saline and drugs were applied through a gravity-fed perfusion system (Valvelink 8.2) using computer-controlled pinch valves. With relatively high perfusion rates $(5 \mathrm{ml} / \mathrm{min})$, low saline levels in the chamber and a short distance between the perfusion manifold and the chamber, it was possible to achieve consistent amplitude, rapid onset responses in oocytes expressing the rapidly desensitizing $\alpha 7$ and ACR-16 nAChRs. Agonists were applied for 10s, and the effects of allosteric modulators were assessed by applying the drug for 30 s immediately prior to a 10 s test 
application of agonist in the continued presence of modulator. Agonist challenges were at $3 \mathrm{~min}$ intervals to minimize any effects of desensitization. Oocytes were only used in experiments if the amplitudes of responses to successive challenges of agonist differed by $10 \%$ or less. All drugs were obtained from Sigma-Aldrich UK except for IVM, PNU-120596 and NS-1738 which were purchased from Tocris (Ellisville, Missouri USA) and acetylcholine chloride which was purchased from Alfa Aesar (Karlsruhe, Germany).

\subsection{Computational protein modelling and Ivermectin docking}

The model of IVM used in this study was constructed using the atom co-ordinates previously determined for avermectin B1a [21]. IVM and avermectin B1a are very similar molecules, differing only at the $\mathrm{C} 22-\mathrm{C} 23$ bond, which is saturated in IVM but unsaturated in avermectin B1a. All IVM atoms conserved in avermectin B1a were therefore assigned the avermectin B1a co-ordinates, leaving only the saturated $\mathrm{C} 22-\mathrm{C} 23$ bond to be modeled. This was readily achieved by simple atom building and local energy minimization with Discovery Studio Visualizer (Accelrys). Figures 2 and 4 were produced using PyMOL (DeLano Scientic).

Modeling of nAChRs was carried out using the molecular modeling software package Sybyl, version 7.3 (Sybyl Molecular Modeling Software, Tripos Associates, Inc., St Louis, Missouri, U.S.A.) and the homology modeling software PDFAMS pro, version 2.0 (Protein Discovery Full Automatic Modeling System, In-Silico Sciences, Inc., Tokyo, Japan), originally developed by Ogata and Umeyama [22]. The three dimensional structures of the nAChRs were constructed based on the sequence and coordinates of the standard protein, AChR (2BG9 [23]) by the simulated annealing method [24] according to Taly et al, 2006 [25]. The receptor model was energy-minimized for 1,000 iterations of conjugated gradients using the MMFF94 force field and 
MMFF94 partial charges $[26,27]$. The coordinates of backbone atoms were fixed during the minimization. The flexible ligand/receptor docking was performed with the FlexiDock, a genetic algorithm-based flexible docking software in Sybyl. IVM was placed manually into the cavity of the ligand binding site. The conformation of IVM was fixed during FlexiDock, except for the torsion angles of the 3-methoxy groups and the sec-butyl group. The docked receptor / ligand models were energy-minimized for 1,000 iterations of conjugated gradients using the MMFF94 force field and MMFF94 partial charges [26, 27] with co-ordinates of the backbone atoms fixed.

\section{Results}

\subsection{Functional studies}

Responses mediated by $\alpha 7$ receptors expressed robustly in oocytes in the presence of RIC-3 were reversibly enhanced by both type I and type II allosteric modulators (Fig. 3). These findings resemble and extend those obtained previously in the absence of RIC-3 $[11,14,17]$. The type I modulators, IVM $(30 \mu \mathrm{M}), 5$-hydroxyindole $(1 \mathrm{mM}), \mathrm{NS}-1738(10 \mu \mathrm{M})$ and genistein $(10 \mu \mathrm{M})$, enhanced $\alpha 7$ responses to $123 \pm 7 \%(n=5), 300 \pm 91 \%,(n=3), 1740 \pm 1358 \%(n=3)$ and $376 \pm$ $77 \%,(\mathrm{n}=3)$ respectively, while the type II modulator, PNU-120596 $(3 \mu \mathrm{M})$ enhanced $\alpha 7$ responses by $1867 \pm 871 \%(\mathrm{n}=4)$. In accordance with previous reports, the type II modulator, PNU-120596 greatly enhanced the duration of the response, while the type I modulators investigated exerted a variable effect upon the time course of the responses, but much less markedly so than type II modulators. The similarity of our findings with type I and type II allosteric modulators and those previously reported $[11,14,17]$ also suggests that RIC-3, which 
enhances the robustness of $\alpha 7$ expression does not affect allosteric responses of the drugs tested in this study.

In contrast to the findings on human $\alpha 7$-mediated responses, ACR-16 showed no positive allosteric modulation of ACh actions by any of the compounds we tested. Rather, all type I PAMs investigated significantly $(\mathrm{P}<0.05,1$-sample $t$-test $)$ attenuated the amplitude of ACR-16mediated ACh response (Fig 3). The results with IVM are in accord with earlier experiments conducted on ACR-16 in the absence of RIC-3 [18]. In addition, there was no obvious effect with the type II modulator, PNU120596, on the time-course of ACh-evoked responses. Reducing or increasing the concentration of the modulators 10-fold did not result in enhancement (data not shown).

\subsection{Computational modelling studies}

The structure of IVM used in this study is based on the crystal structure of Avermectin $\mathrm{B}_{1 \mathrm{a}}$ [21]. A stick representation of the molecule, based on the published crystal co-ordinates [21] is shown (Fig 2). Receptor models for the putative transmembrane region were generated and the IVM molecule docked. IVM is so large and rigid that when manually inserted only a limited complex structure was allowed for docking. Also the Flexidock software yielded only one solution as an initial IVM-docked structure. Whatever method was used to obtain the initial complex structure, the resulting complex structures were always very similar. Of particular interest was the finding that the interaction energies for the $\alpha 7 /$ IVM complex was less than that for ACR16, suggesting that the $\alpha 7$-IVM complex is much more energetically favourable than the ACR-16-IVM complex. 


\section{Discussion}

The cys-loop superfamily of ligand-gated ion channel receptors mediate the fast actions of the neurotransmitters ACh, GABA, glycine and 5-HT in humans. These important transmembrane proteins are the targets of major drugs for the treatment of disorders such as anxiety, nicotine addiction, pain, Alzheimer's disease and schizophrenia. Allosteric drug binding sites on these proteins are of growing importance as targets for new drugs, yet their identity remains to be fully elucidated. Here we begin to explore the combination of comparative pharmacology and computational modelling to better understand the human $\alpha 7$ allosteric drug binding site(s).

\subsection{Major differences in amino acid sequence and the interactions of allosteric ligands between human $\alpha 7$ and C. elegans ACR-16 nAChRs}

We show that drugs exhibiting type I (IVM, 5-HI, genistein, NS-1738) and type II (PNU1205096) PAM activity on human $\alpha 7$ receptor are all without PAM activity on ACR-16, instead displaying varying degrees of attenuation of the amplitude of the ACh response. Genistein and 5HI result in particularly strong attenuation in the amplitude of ACh responses (Fig. 3). In line with this, comparisons reveal that despite an overall sequence identity of $47 \%$ [20], human $\alpha 7$ and $C$. elegans ACR-16 subunits differ at residues known in nAChRs and in other cys-loop receptors to influence the actions of allosteric modulators. For example, ACR-16 differs in 4 of 5 key transmembrane residues, which in rat $\alpha 7$ receptors (these residues are identical in human $\alpha 7$ ) are known to be important in the actions of the PAMs PNU-120596 and LY-2087101 [15] (Fig. 5). Also, the short region at the extracellular end of TM2 and part of the inter TM2-TM3 loop region of $\alpha 7$, which was shown to be involved in NS-1738 potentiation [14], differs by eight amino acid residues when compared to ACR-16. 
Interestingly, the 4 key transmembrane residues highlighted by Young et al [15] (S222 and A225 in TM1, M253 in TM2 and C459 in TM4 after the number in [15]), which are identical in human and rat $\alpha 7$ but differ in C. elegans ACR-16 and are known to influence PAM activity, are in close proximity to (and in some cases overlap with) residues known to influence the actions of other allosteric ligands in a variety of cys-loop receptors. These molecules include anaesthetics [28, 29], alcohols [30], endogenous neurosteroids [16] and androgenic steroids [31] (Fig. 5). Three residues in TM1-3, which have been well-characterised in GABA receptors, form a binding pocket with which general anaesthetics can interact $[16,28]$. Residues in TM1 and TM4 play a major role in the binding of neurosteroids. Residues already identified as determinants of sensitivity to PNU-120596 [15], one of the allosteric modulators employed in the present study are among those that differ between ACR-16 and $\alpha 7$.

Computational modelling suggests differences in interaction energies (Energy (Complex)-Energy (Receptor)-Energy (IVM)) between IVM complexes with $\alpha 7$ andACR-16 nAChRs, with the $\alpha 7$ IVM complex being much more stable than the ACR-16-IVM complex (Fig. 4). Indeed energy considerations suggest that IVM-ACR-16 interactions may be severely limited. However, the small attenuation of the ACh response argues that there must be some interaction between IVM and ACR-16. The sequence differences between $\alpha 7$ and ACR16 invite systematic site-directed mutagenesis studies aimed at elucidating all key residues determining PAM activity and such studies are in progress in our laboratory. Indeed, the valuable insights already gained by comparing $\alpha 7$ nAChRs with a $\alpha 7$ / 5HT3R chimeras [15] encourages the hope that additional insights may be achieved by comparing $\alpha 7$ with ACR16.

\subsection{Ivermectin can have allosteric and agonist effects on ligand-gated ion channels}


IVM acts upon a range of diverse ligand-gated ion channels of both vertebrates and invertebrates, where it can act as an agonist, an allosteric modulator, or both (Table 1). In addition to nematode acetylcholine receptors, these targets also include $\mathrm{P} 2 \mathrm{X}$ receptors of Schistosoma [32] and of mouse ([33]) and histamine-gated chloride channels of Drosophila [34], as well as nematode [35-38] and insect [39, 40] glutamate-gated chloride channels, GABA receptors from nematodes to vertebrates [41-44] and human glycine receptors [45]. There is also evidence for an action of IVM on an intracellular ligand-gated ion channel, the ryanodine receptor [46]. In most cases examined so far, the action of IVM is through an allosteric stabilization of the open state of the channel, but in the case of recombinant nematode glutamategated chloride channels and rat GABA $\alpha_{1} \beta_{1} \gamma_{2}$ receptors, IVM can also act as an agonist [43]. Residues in both transmembrane regions of P2X receptors that affect IVM action have been identified using scanning mutagenesis $[32,47]$. Thus IVM exerts a range of actions on diverse members of the cys-loop receptor family and some other ligand-gated ion channels, providing ample scope for identifying the roles of specific amino acid residues in determining IVM action.

\subsection{Prospects for further understanding of allosteric drug actions and the development of novel allosteric ligands}

The use of $\alpha 7$ / 5-HT3A chimeras has begun to elucidate the site of action of PAMs $[14,15]$. Site-directed mutagenesis informed by comparisons of evolutionarily remote members of the $\alpha 7$ like nAChRs (and other members of the cys-loop family of receptors) combined with pharmacological studies and computational modelling, along with access to resolved structures of relatively rigid molecules such as IVM, will complement the work on such chimeras $[14,15]$. 
Questions of interest include: in the light of its diverse actions (Table 1), does IVM bind to an equivalent site on several types of cys-loop receptor? Can occupation of the transmembrane binding pocket and/or the resultant coupling to channel activation in the different cys-loop receptors account for the observed diversity of IVM actions? It will also be of interest to explore the extent to which computational studies on a complex molecule such as IVM can also add to our understanding of the actions of small molecule allosteric modulators. Mutagenesis and molecular modelling studies in progress on $\alpha 7$ and ACR-16 are aimed at enhancing our understanding of allosteric drug - nAChR interactions and accelerating the development of new allosteric drug candidates.

\section{Acknowledgements}

DBS, SDB and AKJ were supported by the Medical Research Council (MRC) and acknowledge the support of the Wellcome Trust Initiative in Integrative Physiology of Ion Channels (Oxion). KM was supported in part by a Grant-in-Aid for Scientific Research (B) from the Japan Society for Promotion of Science (21310147) and by the Integrated Research Project for Plant, Insect and Animal using Genome Technology from the Ministry of Agriculture, Forestry and Fisheries of Japan (1302). 


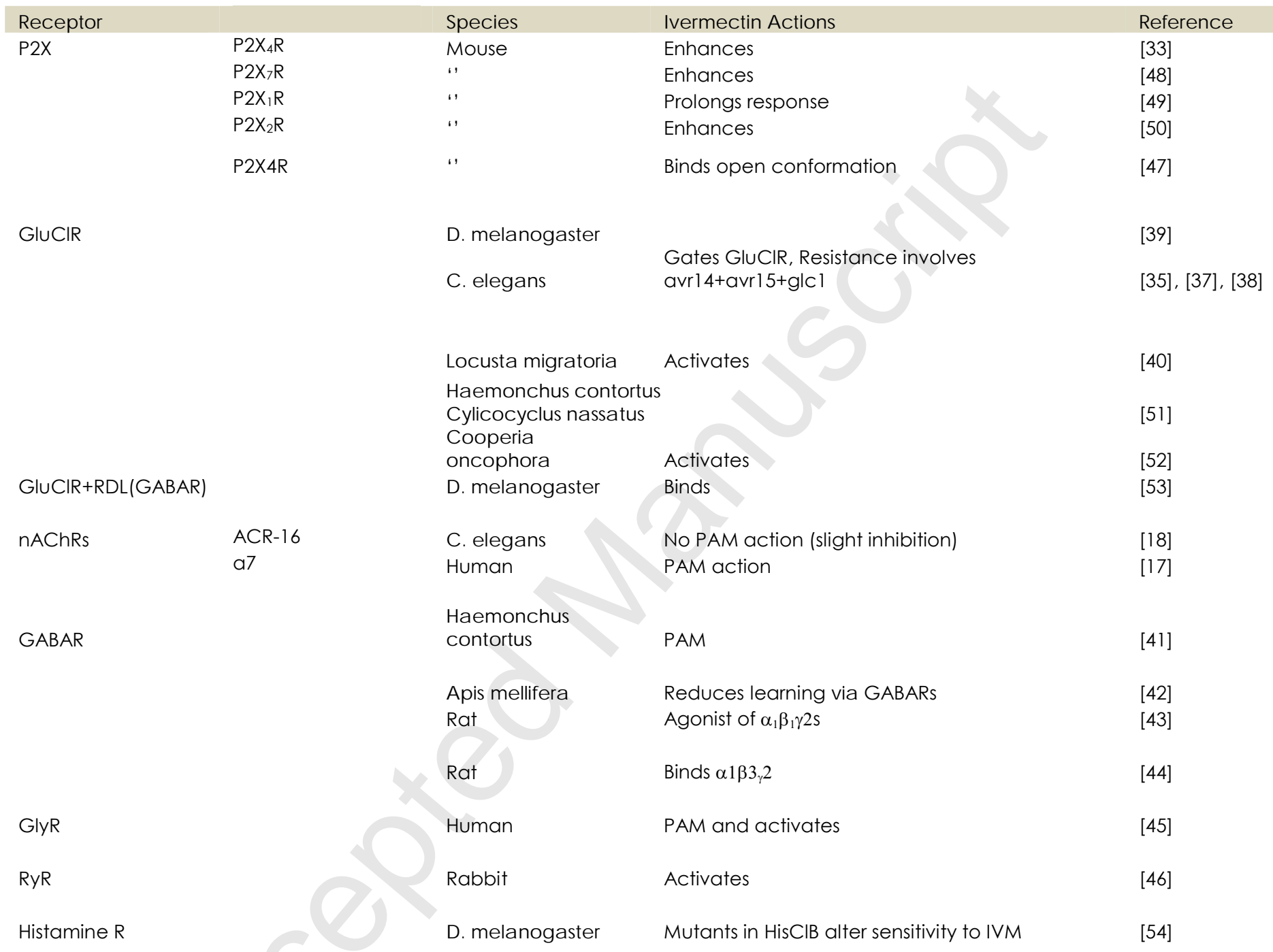

\section{Figure captions}

Fig. 1. Alignment of the amino acid sequences of the human $\alpha 7$ and C. elegans ACR-16 homomer - forming $n A C h R$ subunits. The signal sequences (brown box), acetylcholine binding loops A-F 
(purple boxes) and transmembrane regions TM1-4 (blue boxes) are indicated. The alignment and feature annotation were performed using the SWISSPROT database. Although the signal sequence is illustrated, the numbering of residues shown is that of the mature peptide.

Fig. 2. Structure of Ivermectin. The stick model was constructed from the co-ordinates of avermectin B1a [21]. Carbon atoms are coloured grey and oxygen atoms red. Hydrogen atoms have been omitted for clarity.

Fig. 3. Major differences are observed in the actions of type 1 and type 2 allosteric modulators on human $\alpha 7$ and C. elegans receptors. The actions of PNU120596 (type 2 action characterised by enhanced amplitude and duration of the ACh response) as well as IVM, 5-HI, genistein and NS-1738 (type1 actions characterised by enhanced amplitude) as positive allosteric modulators of the human $\alpha 7 \mathrm{nAChR}$ contrast strikingly with their blocking actions on the C. elegans ACR$16 \mathrm{nAChR}$.

Fig. 4. The docking of Ivermectin to $\alpha 7$ and ACR-16 nAChRs. Top and side views of the complexes are shown in the upper and lower parts of this figure. IVM was docked into $\alpha 7$ and ACR-16 using the PDFAMS software (see Methods for details). Only one subunit is shown to facilitate observation. IVM is drawn as sticks where carbons and oxygens are colored white and red, respectively, while omitting hydrogens. The transmembrane (TM1) regions are shown as cyan helices, while the TM2-TM3 linker is shown as sticks where carbons, nitrogens and oxygens are colored green, blue and red, respectively. The two models differed in their interaction energies ( $\alpha$ 7-IVM complex: $-68.4 \mathrm{kcal} / \mathrm{mol}$; ACR16-IVM complex: $-19.1 \mathrm{kcal} / \mathrm{mol}$ ). 
Fig. 5. Sequence alignment of the transmembrane regions of human $\alpha 7$ and C. elegans $A C R-16$ showing residues in transmembrane regions (red boxes, [15]) and segments between transmembrane regions (yellow boxes[14]) that are known to mediate the effects of positive allosteric modulators (PAMS). In addition, equivalent residues in other ligand-gated ion channels that have been implicated in the actions of allosteric modulators are also indicated. These sites include a well-characterized binding cavity to which residues in the extracellular portions of TM1-3 contribute. The close proximity of residues in different receptors mediating different allosteric actions suggests that common binding sites are conserved across different members of the cys-loop family. That $\alpha 7$ and ACR16, despite their overall sequence similarity, should 1) differ at most of these sites, 2) have widely different pharmacologies and 3) robustly form functional homomers underscores the great usefulness of these receptors in exploring the molecular basis of PAM action. Residue numbering is that for the mature peptide.

Table 1 The diverse actions of ivermectin (IVM) on cys-loop neurotransmitter receptors and other ligand-gated ion channels. In most cases, IVM is a positive allosteric modulator, although there is some evidence that it can also act as an agonist. This diversity of IVM targets includes both excitatory and inhibitory neurotransmitter receptors and includes both vertebrate and invertebrate targets. There is therefore scope for comparative studies on related, but distinct, cys-loop receptor subunits. Abbreviations: CHO: Chinese hamster ovary; GABAR: GABA receptor; GluClR: glutamate-gated chloride channel; GlyR: glycine receptor; HClB: histaminegated chloride channel B; nAChRs: nicotinic acetylcholine receptors; PAM: positive allosteric modulator; P2XR: P2X receptor; RDL: resistant to dieldrin; RyR: ryanodine receptor; TM: transmembrane regions.

\section{References}


[1] Dani JA, Bertrand D. Nicotinic acetylcholine receptors and nicotinic cholinergic mechanisms of the central nervous system. Annu Rev Pharmacol Toxicol 2007;47:699-729.

[2] Hogg RC, Raggenbass M, Bertrand D. Nicotinic acetylcholine receptors: from structure to brain function. Rev Physiol Biochem Pharmacol 2003;147:1-46.

[3] Levin ED, Chen E. Nicotinic involvement in memory function in zebrafish. Neurotoxicol Teratol 2004;26:731-5.

[4] Dickinson JA, Kew JNC, Wonnacott S. Presynaptic $\alpha 7$ - and $\beta 2$-containing nicotinic acetylcholine receptors modulate excitatory amino acid release from rat prefrontal cortex nerve terminals via distinct cellular mechanisms. Mol Pharmacol 2008;74:348-59.

[5] Jones IW, Wonnacott S. Precise localization of $\alpha 7$ nicotinic acetylcholine receptors on glutamatergic axon terminals in the rat ventral tegmental area. $J$ Neurosci 2004;24:1 1244-52.

[6] Kaiser S, Wonnacott S. alpha-bungarotoxin-sensitive nicotinic receptors indirectly modulate $\left[{ }^{3} \mathrm{H}\right]$ dopamine release in rat striatal slices via glutamate release. Mol Pharmacol 2000;58:312-8.

[7] Buckingham SD, Jones AK, Brown LA, Sattelle DB. Nicotinic acetylcholine receptor signalling: roles in Alzheimer's disease and amyloid neuroprotection. Pharmacol Rev 2009;61:39-61.

[8] Martin LF, Kem WR, Freedman R. Alpha-7 nicotinic receptor agonists: potential new candidates for the treatment of schizophrenia. Psychopharmacology (Berl) 2004; 174:54-64.

[9] Severance EG, Yolken RH. Novel $\alpha 7$ nicotinic receptor isoforms and deficient cholinergic transcription in schizophrenia. Genes Brain Behav 2008;7:37-45.

[10] Salas R, Main A, Gangitano D, De Biasi M. Decreased withdrawal symptoms but normal tolerance to nicotine in mice null for the $\alpha 7$ nicotinic acetylcholine receptor subunit. Neuropharmacology 2007;53:863-9.

[11] Bertrand D, Gopalakrishnan M. Allosteric modulation of nicotinic acetylcholine receptors. Biochem Pharmacol 2007;74:1155-63.

[12] Hogg RC, Buisson B, Bertrand D. Allosteric modulation of ligand-gated ion channels. Biochem Pharmacol 2005;70:1267-76.

[13] Gronlien JH, Hakerud M, Ween H, Thorin-Hagene K, Briggs CA, Gopalakrishnan M, et al. Distinct profiles of $\alpha 7 \mathrm{nAChR}$ positive allosteric modulation revealed by structurally diverse chemotypes. Mol Pharmacol 2007;72:715-24.

[14] Bertrand D, Bertrand S, Cassar S, Gubbins E, Li J, Gopalakrishnan M. Positive allosteric modulation of the $\alpha 7$ nicotinic acetylcholine receptor: ligand interactions with distinct binding sites and evidence for a prominent role of the M2-M3 segment. Mol Pharmacol 2008;74:1407-16.

[15] Young GT, Zwart R, Walker AS, Sher E, Millar NS. Potentiation of $\alpha 7$ nicotinic acetylcholine receptors via an allosteric transmembrane site. Proc Natl Acad Sci U S A 2008;105:14686-91.

[16] Hosie AM, Clarke L, da Silva H, Smart TG. Conserved site for neurosteroid modulation of GABA A receptors. Neuropharmacology 2009;56:149-54.

[17] Krause RM, Buisson B, Bertrand S, Corringer P-J, Galzi J-L, Changeux J-P, et al. Ivermectin: a positive allosteric effector of the $\alpha 7$ neuronal nicotinic acetylcholine receptor. Mol Pharmacol 1998;53:283-94. 
[18] Raymond V, Mongan NP, Sattelle DB. Anthelmintic actions on homomer-forming nicotinic acetylcholine receptor subunits: chicken $\alpha 7$ and ACR-16 from the nematode Caenorhabditis elegans. Neuroscience 2000;101:785-91.

[19] Ballivet M, Alliod C, Bertrand S, Bertrand D. Nicotinic acetylcholine receptors in the nematode Caenorhabditis elegans. J Mol Biol 1996;258:261-9.

[20] Mongan NP, Jones AK, Smith GR, Sansom MS, Sattelle DB. Novel $\alpha$-like nicotinic acetylcholine receptor subunits in the nematode Caenorhabditis elegans. Protein Sci 2002;1 1:1162-71.

[21] Springer JP, Arison BH, Hirshfield JM, K. H. The absolute stereochemistry and conformation of Avermectin $B_{2 a}$ Aglycon and Avermectin B $B_{1 a}$. J Am Chem Soc 1981;103:4221-4.

[22] Ogata K, Umeyama H. An automatic homology modeling method consisting of database searches and simulated annealing. J Mol Graph Model 2000;18:258-72, 305-6.

[23] Unwin N. Refined structure of the nicotinic acetylcholine receptor at 4A resolution. J Mol Biol 2005;346:967-89.

[24] Kirkpatrick S, Gelatt CD, Jr., Vecchi MP. Optimization by simulated annealing. Science 1983;220:671-80.

[25] Taly A, Corringer P-J, Grutter T, de Carvalho LP, Karplus M, Changeux J-P. Implications of the quaternary twist allosteric model for the physiology and pathology of nicotinic acetylcholine receptors. Proceedings of the National Academy of Sciences 2006;103:16965-70.

[26] Halgren TA. MMFF VI. MMFF94s option for energy minimization studies. Journal of Computational Chemistry 1999;20:720-9.

[27] Halgren TA. MMFF VII. Characterization of MMFF94, MMFF94s, and other widely available force fields for conformational energies and for intermolecularinteraction energies and geometries. Journal of Computational Chemistry 1999;20:730-48.

[28] Jenkins A, Greenblatt EP, Faulkner HJ, Bertaccini E, Light A, Lin A, et al. Evidence for a common binding cavity for three general anesthetics within the GABAA receptor. J Neurosci 2001;21:RC136.

[29] Krasowski MD, Nishikawa K, Nikolaeva N, Lin A, Harrison NL. Methionine 286 in transmembrane domain 3 of the $\mathrm{GABA}_{\mathrm{A}}$ receptor beta subunit controls a binding cavity for propofol and other alkylphenol general anesthetics. Neuropharmacology 2001;41:952-64.

[30] Mihic SJ, Ye Q, Wick MJ, Koltchine VV, Krasowski MD, Finn SE, et al. Sites of alcohol and volatile anaesthetic action on $G_{A B A}$ and glycine receptors. Nature 1997:389:385-9.

[31] Jones BL, Whiting PJ, Henderson LP. Mechanisms of anabolic androgenic steroid inhibition of mammalian epsilon-subunit-containing GABA $A_{A}$ receptors. J Physiol 2006;573:571-93.

[32] Jelinkova I, Vavra V, Jindrichova M, Obsil T, Zemkova HW, Zemkova H, et al. Identification of P2X(4) receptor transmembrane residues contributing to channel gating and interaction with ivermectin. Pflugers Arch 2008;456:939-50.

[33] Lalo U, Verkhratsky A, Pankratov Y. Ivermectin potentiates ATP-induced ion currents in cortical neurones: evidence for functional expression of P2X4 receptors? Neurosci Lett 2007;421:158-62. 
[34] Iovchev M, Kodrov P, Wolstenholme AJ, Pak WL, Semenov EP. Altered drug resistance and recovery from paralysis in Drosophila melanoga ster with a deficient histamine-gated chloride channel. J Neurogenet 2002;16:249-61.

[35] Cully DF, Paress PS, Liu KK, Schaeffer JM, Arena JP. Identification of a Droso phila mela noga ster glutamate-gated chloride channel sensitive to the antiparasitic agent avermectin. J Biol Chem 1996;271:20187-91 .

[36] Cook A, Aptel N, Portillo V, Siney E, Sihota R, Holden-Dye L, et al. Caenorhabditis elegans ivermectin receptors regulate locomotor behaviour and are functional orthologues of Haemonc hus c ontortus receptors. Mol Biochem Parasitol 2006;147:1 18-25.

[37] Pemberton DJ, Franks CJ, Walker RJ, Holden-Dye L. Characterization of glutamate-gated chloride channels in the pharynx of wild-type and mutant Caenorhabditis elegans delineates the role of the subunit $\mathrm{GluCl}-\alpha 2$ in the function of the native receptor. Mol Pharmacol 2001:59:1037-43.

[38] Dent JA, Smith MM, Vassilatis DK, Avery L. The genetics of ivermectin resistance in Caenorhabditis elegans. Proc Natl Acad Sci U S A 2000;97:2674-9.

[39] Kane NS, Hirschberg B, Qian S, Hunt D, Thomas B, Brochu R, et al. Drug-resistant Drosophila indicate glutamate-gated chloride channels are targets for the antiparasitics nodulisporic acid and ivermectin. Proc Natl Acad Sci U S A 2000;97:13949-54.

[40] Janssen D, Derst C, Buckinx R, Van den Eynden J, Rigo JM, Van Kerkhove E. Dorsal unpaired median neurons of Locusta migra toria express ivermectin- and fipronil-sensitive glutamate-gated chloride channels. J Neurophysiol 2007;97:2642-50.

[41] Feng XP, Hayashi J, Beech RN, Prichard RK. Study of the nematode putative GABA type-A receptor subunits: evidence for modulation by ivermectin. J Neurochem 2002;83:870-8.

[42] El Hassani AK, Giurfa M, Gauthier M, Armengaud C. Inhibitory neurotransmission and olfactory memory in honeybees. Neurobiol Learn Mem 2008;90:589-95.

[43] Adelsberger $H$, Lepier A, Dudel J. Activation of rat recombinant $\alpha_{1} \beta_{2 \gamma_{2 S}}$ GABA(A) receptor by the insecticide ivermectin. Eur J Pharmacol 2000;394:163-70.

[44] Dawson GR, Wafford KA, Smith A, Marshall GR, Bayley PJ, Schaeffer JM, et al. Anticonvulsant and adverse effects of avermectin analogs in mice are mediated through the gamma-aminobutyric acid(A) receptor. J Pharmacol Exp Ther 2000;295:1051-60.

[45] Shan Q, Haddrill JL, Lynch JW. Ivermectin, an unconventional agonist of the glycine receptor chloride channel. J Biol Chem 2001;276:12556-64.

[46] Ahern GP, Junankar PR, Pace SM, Curtis S, Mould JA, Dulhunty AF. Effects of ivermectin and midecamycin on ryanodine receptors and the $\mathrm{Ca}^{2+}$-ATPase in sarcoplasmic reticulum of rabbit and rat skeletal muscle. J Physiol 1999;514 ( Pt 2):313-26.

[47] Silberberg SD, Li M, Swartz KJ. Ivermectin Interaction with transmembrane helices reveals widespread rearrangements during opening of $\mathrm{P} 2 \mathrm{X}$ receptor channels. Neuron 2007;54:263-74.

[48] Guo C, Masin M, Qureshi OS, Murrell-Lagnado RD. Evidence for functional P2X4/P2X7 heteromeric receptors. Mol Pharmacol 2007;72:1447-56. 
[49] Sim JA, Park CK, Oh SB, Evans RJ, North RA. P2X1 and P2X4 receptor currents in mouse macrophages. Br J Pharmacol 2007;152:1283-90.

[50] De Roo M, Rodeau JL, Schlichter R. Dehydroepiandrosterone potentiates native ionotropic ATP receptors containing the P2X2 subunit in rat sensory neurones. J Physiol 2003;552:59-71.

[51] Tandon R, LePage KT, Kaplan RM. Cloning and characterization of genes encoding alpha and beta subunits of glutamate-gated chloride channel protein in Cylic ocyc lus nassa tus. Mol Biochem Parasitol 2006;150:46-55.

[52] Njue Al, Hayashi J, Kinne L, Feng XP, Prichard RK. Mutations in the extracellular domains of glutamate-gated chloride channel $\alpha 3$ and $\beta$ subunits from ivermectin-resistant Cooperia oncophora affect agonist sensitivity. J Neurochem 2004;89:1 137-47.

[53] Ludmerer SW, Warren VA, Williams BS, Zheng Y, Hunt DC, Ayer MB, et al. Ivermectin and nodulisporic acid receptors in Drosophila mela noga ster contain both gamma-aminobutyric acid-gated Rdl and glutamate-gated GluCl alpha chloride channel subunits. Biochemistry 2002;41:6548-60.

[54] Yusein S, Velikova N, Kupenova P, Hardie R, Wolstenholme A, Semenov E. Altered ivermectin pharmacology and defective visual system in Drosophila mutants for histamine receptor HCLB. Invert Neurosci 2008;8:211-22. 


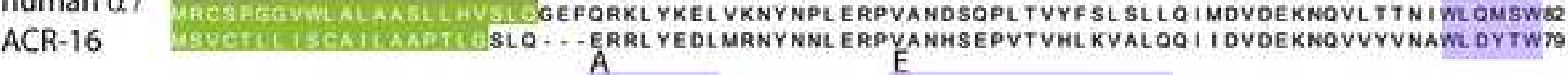

61 TDHYLOWNY SEYPGYKTYRFPDGO IWK PDILLYNSADERFDATFHTNYL VNSSGHCOYLPPG IFKS SCYIDYRWFPFDVOHC 164 61 NDYNL VWDKAEYGN I TOYRFPAGK I WKPOVLL YNSVDTNFDSTYQTNMIVYSTGLVAWVPPGIFKISCKIDIOWFPFDEQKC 161 $\mathrm{B}$ $F$ C TM1

143 KL KFGSWSYGOWSL DL OMOEA - - DISGY I PNGEWOL VG I PGKRSERFYECCKEPYPDVTFT VTMRRRT 143 FFKFGSWTYDGYKL DLOPATGGFDISEY ISNGEWAL PLTTVERNEKFYDCCPEPYPDVHFYL HMRRRTL TM2

$$
\text { TM2 TM3 }
$$

223
225

EIMPATSOSVPLIAQ 243

305 MPKWT RY $1 L L$ LWCAWELRMXRPGE \#. OKVRPACQHKORRCSLASVEMSAVAPPPASNGNLLYIGF RGL DGVHCYPTPDSG 404 307 MG PWT RNLL $L$ YWI PWILRMKRPGHNL TYASLPSLFSTKPNRHSESL I RNI KDNEHSL SRANSFDADCRL NOYIMTOSVSNGL 407 383 VVCGRMACSPT HDEHLL HGGQPPEGDPDL AK I LEEVRYIANRFRCQDE SEAVCSEWKFAACVVDR 389 TSLGSIPSTM ISSNGTTTOVSQQATLL I LHRIYHEL KIVTKRMI EGOKEEQACNNWKFAAMVVOR

\begin{tabular}{l|l|l|l}
465 & PNFVEAVSKDFA & binding & Transmembrane \\
471 & PYLVA........ & loops & regions
\end{tabular}




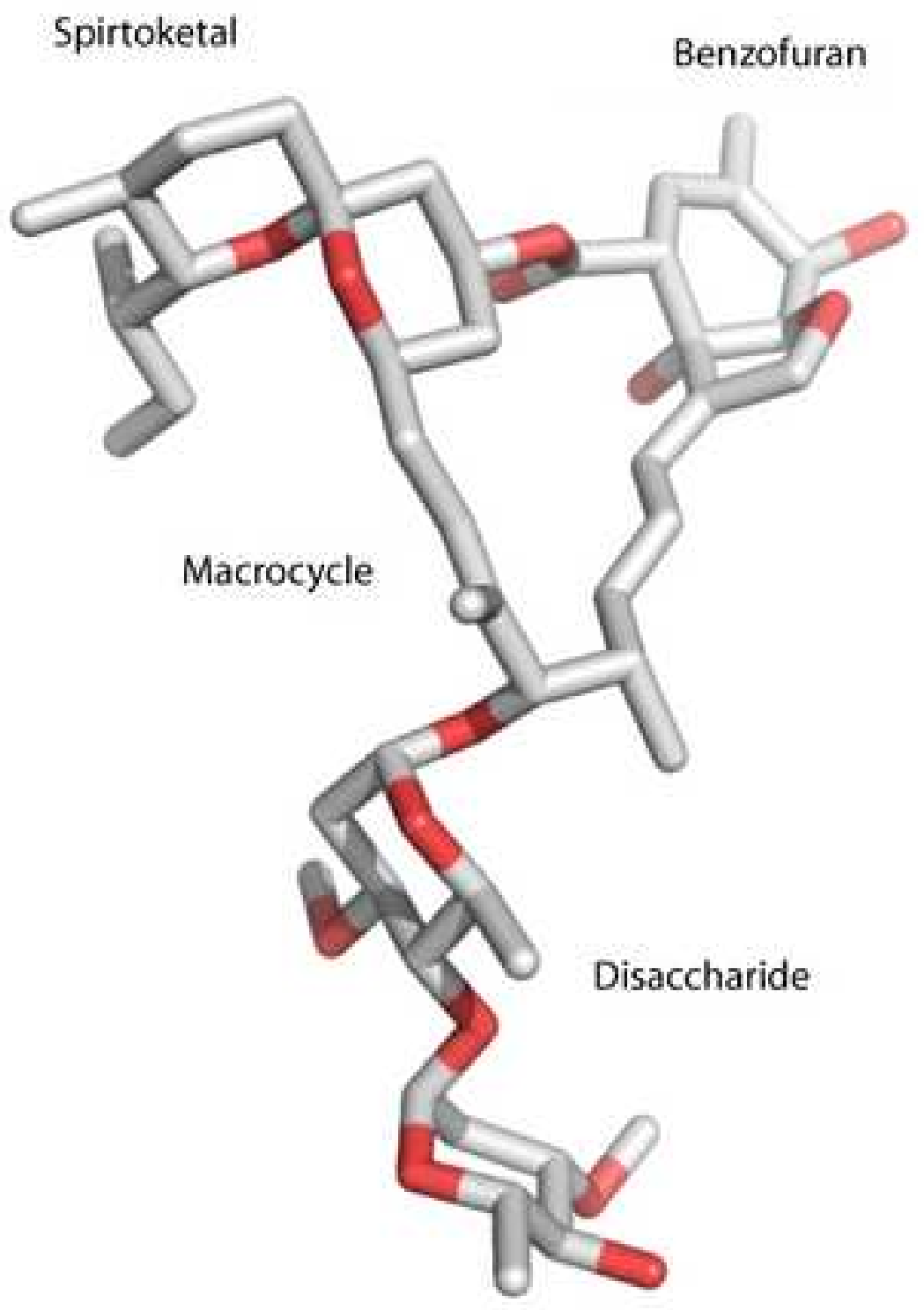

rage $2<$ or $2 b$ 

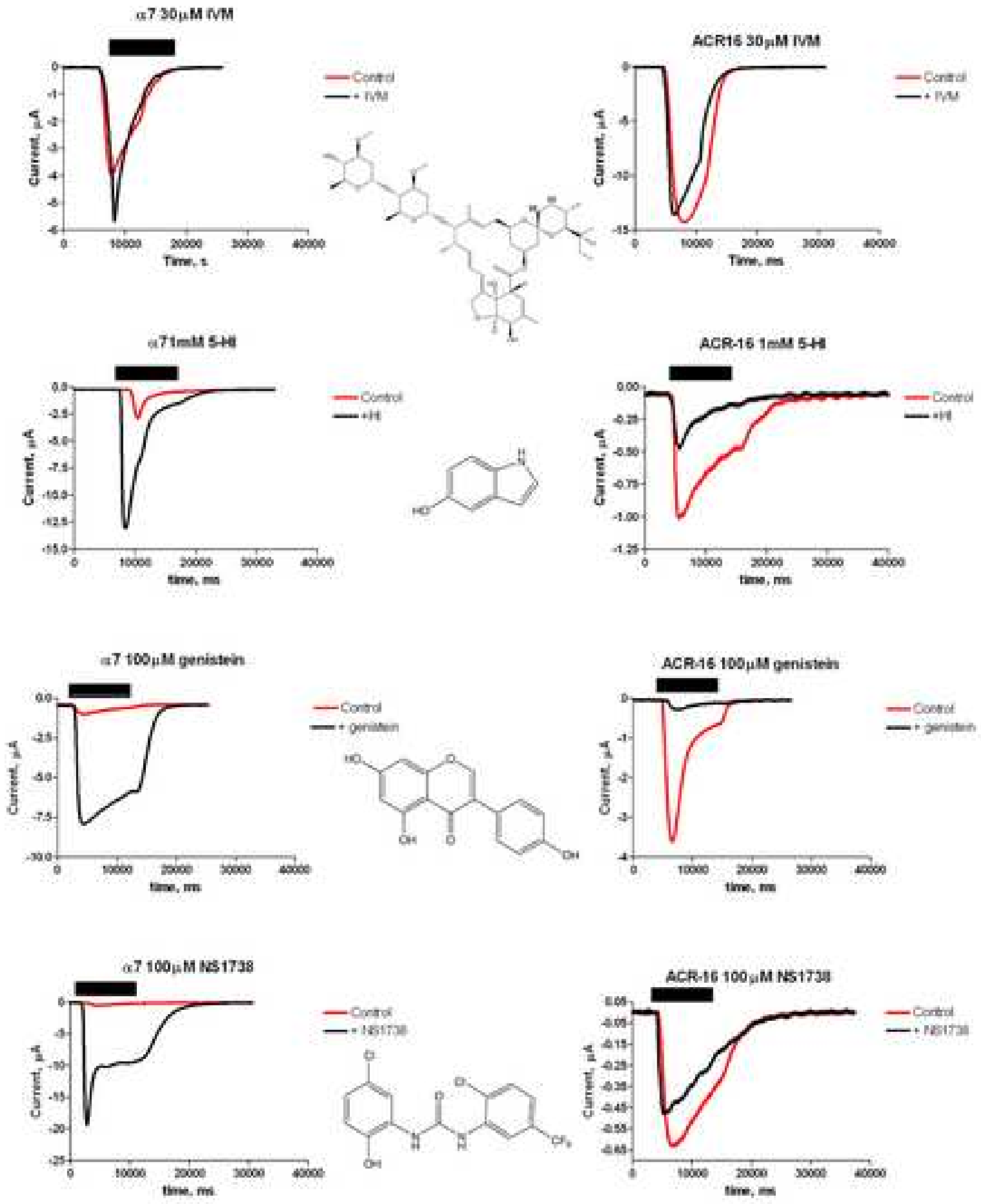

47 3wM PNur2059s<smiles>Oc1ccc2[nH]ccc2c1</smiles>

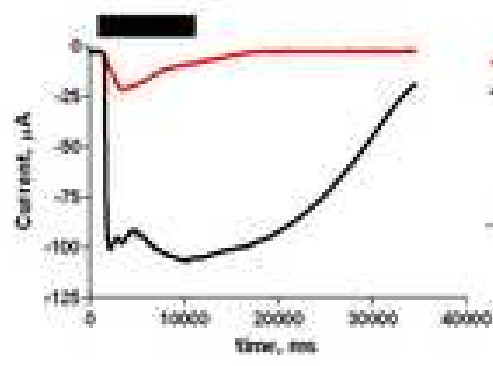

- Costes

- +54
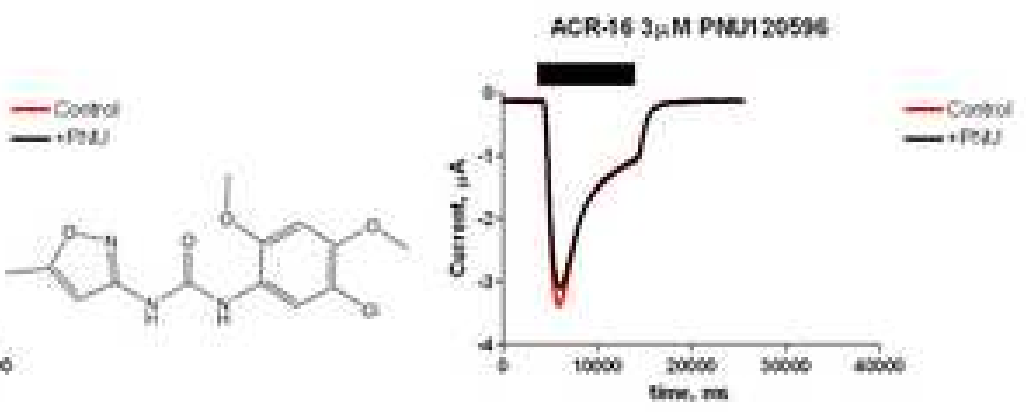


\section{$\alpha 7$ \\ ACR-16}
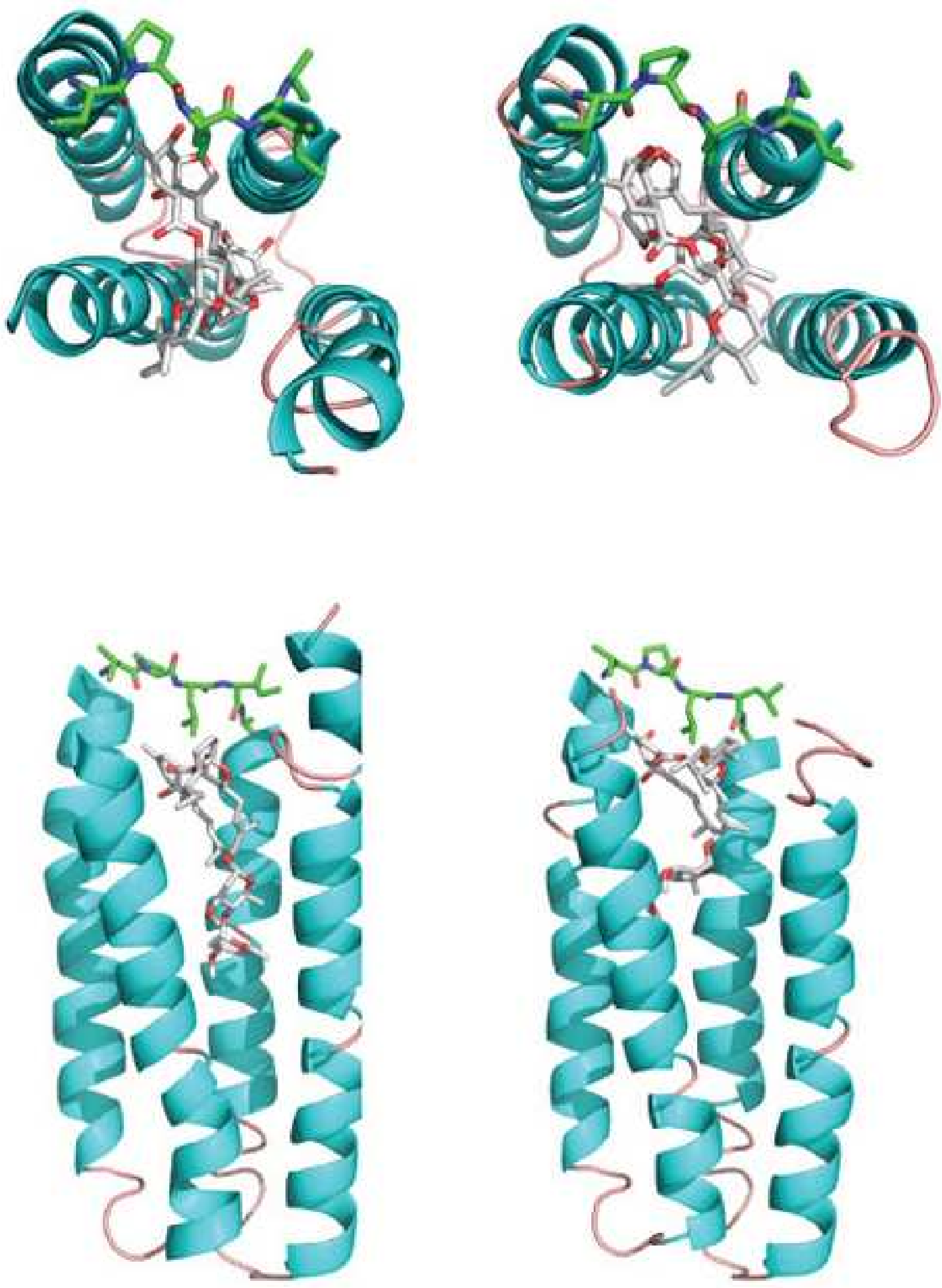

Page 24 of 26 
Anaesthetics, 5-Hydroxyindole (SHT3A)

Enflurane, Trichloroethanol (GlyR)

Endogenous neurosteroids (GABAA)

Halothane, isoflurane,

chloroform (GABAA) ACR-16

Ethanol, enflurane. isoflurane, halothane, chloroform (GABAA)
Trichloroethanol

(GlyR)

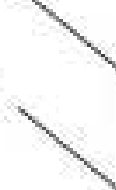

Anabolic androgenic steroids (GABAA)
Anabolic androgenic steroids (GABAA) human $\alpha 7_{143}$ KLKKGSWSYGGWSL DL QMQEA - DISGYIPNGEWDL VGI PGKRSERFYECCKEPYPDVTETVTMRRRT
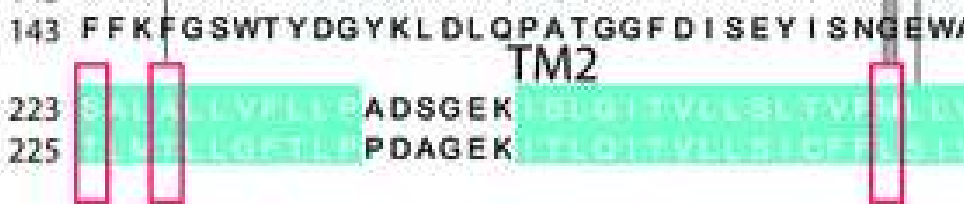

\section{EIMPATSDSVPLIAC EMSPPTSEAVPLLG I}

Halothane, isoflurane, chloroform (GABAA)

305 MPKWTRVILLNWCAWFLRMKRPGE ... DKVRPACQHKQRRCSLASVEMSAVAPPPASNGNLLYIGFRGL DGVHCVP PDSG 404 307 MGPWT RNLLLYWI PWILRMKRPGHNLTYASLPSLFSTKPNRHSESL I RN I KDNEHSL SRANSFDADCRL NQYI MTQSYSNGL 407

383 VVCGRMACSPTHDEHLL HGGQPPEGDPDLAKILEEVRYIANRFRCQDESEAVCSEWKFAACVVDR 389 TSLGS IPSTMISSNGTTTDVSQQATLL ILHRIYHELK IVTKRM I EGDKEEQACNNWKFAAMVVDR

$$
\text { TM4 }
$$

Endogenous

Endogenous neurosteroids neurosteroids

(GABAA) (GABAA)

Region in $\alpha 7$ affecting

PAM actions
465 PNFVEAYSKDFA Transmembrane
471
PYLVA...... regions

Residues in $\alpha 7$ affecting

PAM actions

(Young et al, 2008)
(Bertrand et al, 2008) 


\section{$\alpha 7$}

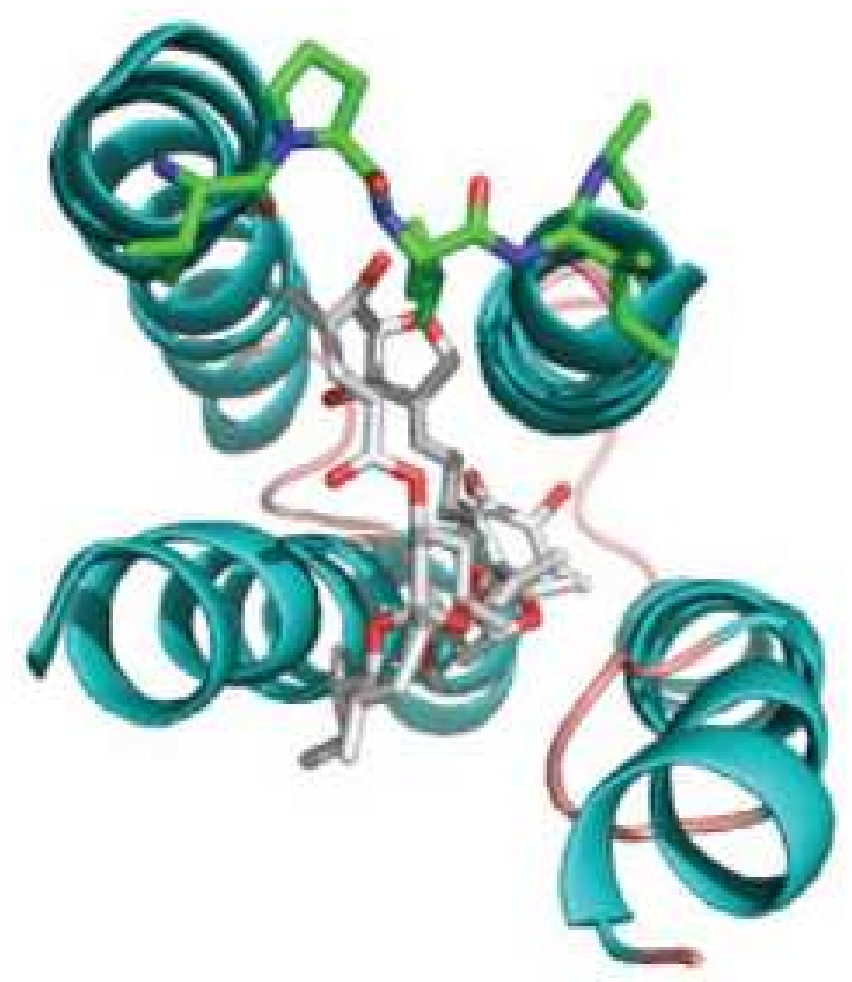

ACR-16

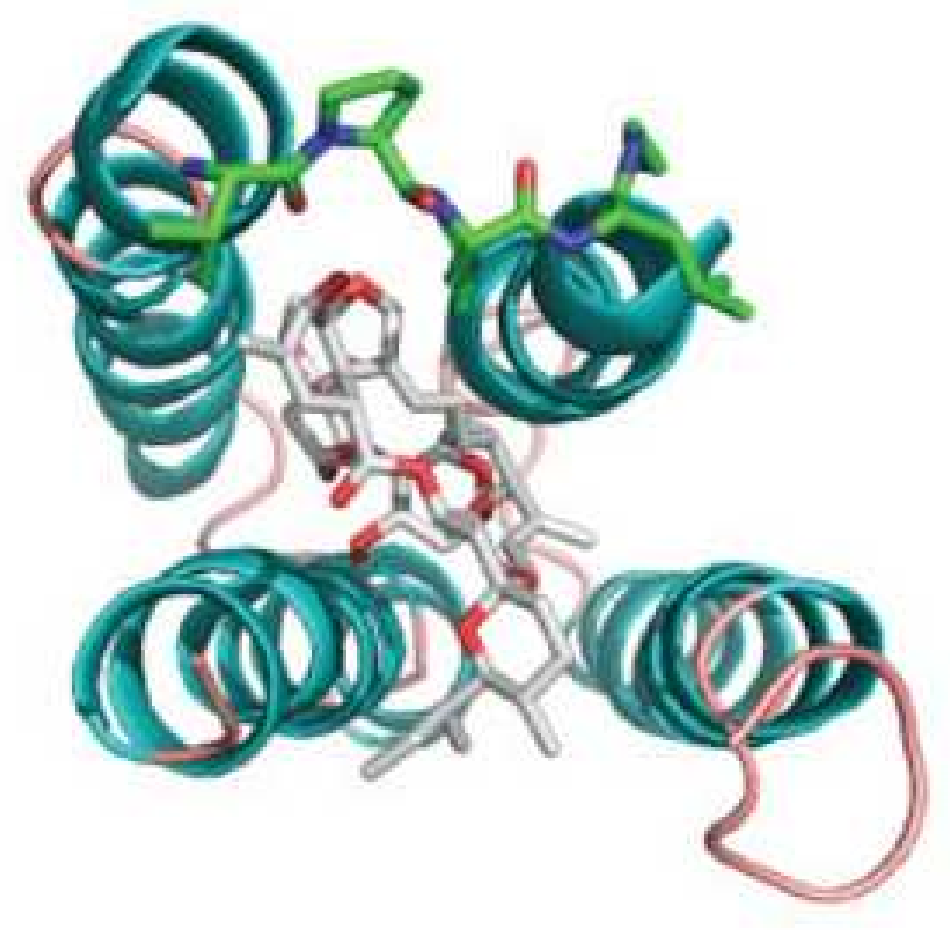

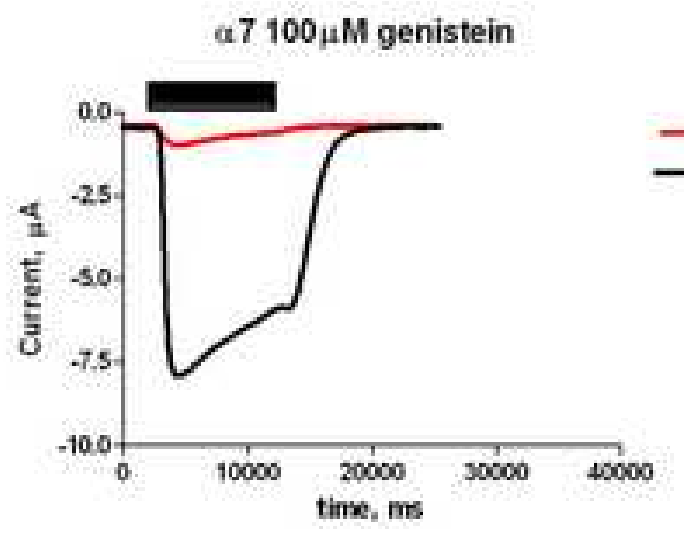
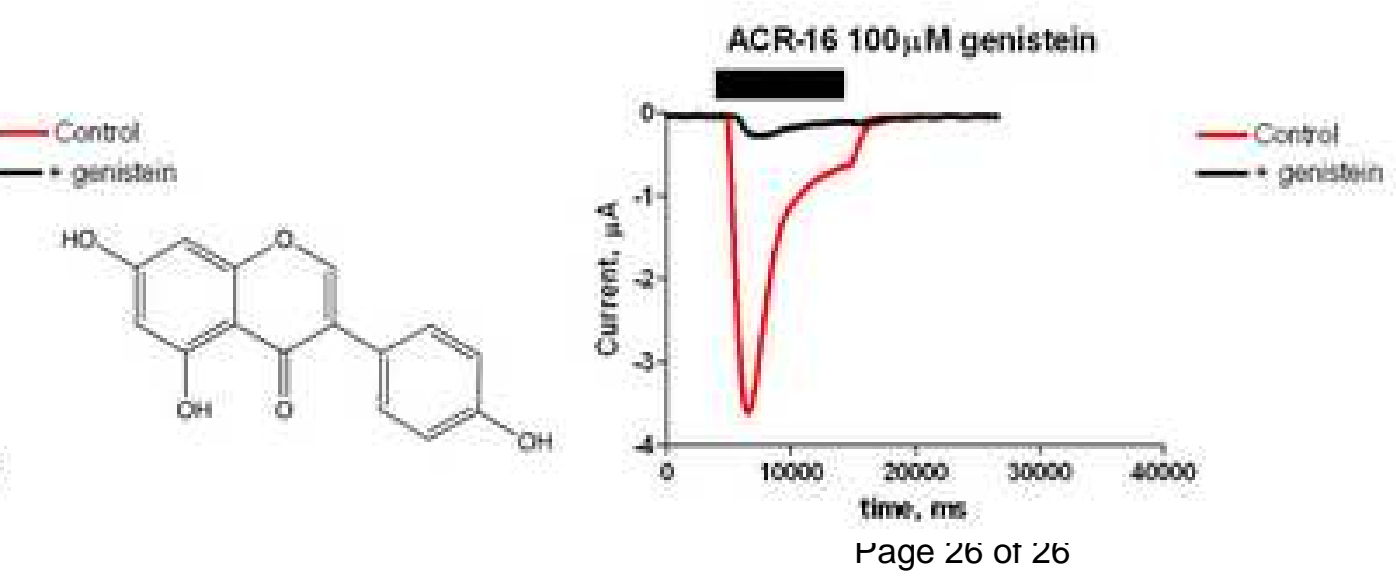